\title{
Effect of age on the association of non-high-density-lipoprotein cholesterol and apolipoprotein B with cardiovascular mortality in a Mediterranean population with type 2 diabetes: the Casale Monferrato study
}

Received: 7 September 2005 / Accepted: 14 January 2006 / Published online: 9 March 2006

(C) Springer-Verlag 2006

\begin{abstract}
Aims/hypothesis: Measurement of plasma apolipoprotein (Apo) B may improve prediction of cardiovascular risk, as it provides a measure of the total number of atherogenic particles. The aim of this population-based study was to compare the association of non-HDLcholesterol, ApoB and the ApoB:ApoA-I ratio with cardiovascular mortality in people with type 2 diabetes. Subjects and methods: We assessed the association of lipids, lipoprotein lipids and apolipoproteins with 11-year mortality from cardiovascular disease in the populationbased cohort of the Casale Monferrato Study (1,565 people with diabetes; median age 68.9 years), and determined the effect of age ( $\leq 70$ and $>70$ years) on these relationships. Results: On the basis of 341 deaths from cardiovascular disease in 10,809 person-years of observation, there was a decreasing trend in risk adjusted for multiple factors across quartiles of total cholesterol, and LDL- and non-HDL-cholesterol in people aged $>70$ years, but no trend in those aged $\leq 70$ years. Age did not affect the protective effect of HDL-cholesterol. ApoB and ApoB:ApoA-I were associated with outcome in
\end{abstract}

G. Bruno $(\bowtie) \cdot$ S. Prina-Cerai · G. Pagano $\cdot$ P. Cavallo-Perin Department of Internal Medicine, University of Turin, corso Dogliotti 14

I-10126 Turin, Italy

e-mail: graziella.bruno@unito.it

Tel.: +39-011-6637434

Fax: +39-011-6634751

F. Merletti

Unit of Cancer Epidemiology, CERMS,

University of Turin,

Turin, Italy

\section{A. Biggeri}

Department of Statistics G. Parenti,

University of Florence,

Florence, Italy

\section{G. Bargero}

Santo Spirito Hospital,

Casale Monferrato,

Alessandria, Italy people in both age groups independently of non-HDLcholesterol. After adjustment for multiple factors, including non-HDL-cholesterol, the hazard ratios for ApoB: ApoA-I in the upper vs lower quartile were $2.98(95 \% \mathrm{CI}$ $1.15-7.75 ; p$ for trend $=0.009$ ) for people aged $\leq 70$ years and $1.94(95 \%$ CI $1.20-3.13 ; p$ for trend $=0.003)$ for those aged $>70$ years. Conclusions/interpretation: In this cohort of Mediterranean subjects with diabetes, ApoB and the ApoB:ApoA-I ratio were associated with cardiovascular disease mortality independently of non-HDLcholesterol. Our findings support the recommendation that ApoB and ApoA-I should be measured routinely in all people with diabetes, particularly in the elderly.

Keywords ApoB · Cohort · Epidemiology · Lipids · Lipoproteins · Survey

Abbreviations AER: albumin excretion rate ·

Apo: apolipoprotein $\cdot$ HR: Hazard ratio $\cdot$ ICD: International classification of diseases

\section{Introduction}

The association between LDL-cholesterol and cardiovascular disease in people aged $<70$ years of age is well established [1]. This association is weaker in older people, with an apparent paradoxical protective effect of high concentrations of cholesterol in some observational studies [2-7]. Measurement of plasma apolipoprotein (Apo) B and ApoA-I improves the prediction of cardiovascular disease, allowing identification of high-risk individuals who are not identified by the standard lipid profile [8-10]. As there is one molecule of ApoB per atherogenic particle, plasma ApoB concentrations provide a measure of the total number of atherogenic particles. A series of studies have shown that $A p o B$ is a more accurate index of atherogenic risk than total cholesterol or LDL-cholesterol $[10,11]$, and, in a multivariate analysis including hypertension, smoking, central obesity, diabetes, psychosocial and dietary factors, a 
linear relationship was found between risk for cardiovascular disease and ApoB:ApoA-I [12].

As small, dense LDL particles, which are strongly associated with cardiovascular disease, contain less cholesterol than large buoyant LDL, measurement of LDLcholesterol will clearly result in underestimation of the risk due to LDL $[13,14]$. To overcome this limitation and to take into account the cholesterol in VLDL, the Expert Panel on Detection, Evaluation, and Treatment of High Blood Cholesterol in Adults (Adult Treatment Panel III) recommended that non-HDL-cholesterol be used instead of LDL-cholesterol for people with the metabolic syndrome [15]. Non-HDL-cholesterol is the sum of all the cholesterol in atherogenic lipoprotein particles (LDL, lipoprotein(a), VLDL and intermediate-density lipoprotein). Since there is a strong correlation between non-HDL-cholesterol and ApoB, the Adult Treatment Panel III concluded that nonHDL-cholesterol is an acceptable substitute for ApoB [15].

This choice was made in the absence of clinical data. Since that time, a substantial number of reports have indicated that ApoB and non-HDL-cholesterol are better predictors than LDL-cholesterol in people with diabetes [16-19]. Few studies have been conducted, however, to compare non-HDL-cholesterol with ApoB [18, 19]; the studies that have been reported were restricted to North America, and the results were mixed. It would be misleading to generalise the findings to other populations, for a number of reasons. First, both the general populations and people with diabetes living in the Mediterranean region have a lower risk for cardiovascular disease than those living in northern Europe and in the USA [20,21]. Second, there may have been selection bias in forming the cohorts. Third, most of the studies were focused on middle-aged people with diabetes, limiting an assessment of the effect of age. In Mediterranean countries such as Italy, almost 50\% of people with diabetes are aged $>70$ years.

We previously identified a population-based cohort of individuals with known diabetes, who are representative of such people in Italy. This cohort has been followed prospectively to determine 11-year mortality from all causes and from cardiovascular disease [22-24]. As the association of the ApoB:ApoA-I ratio has not been studied in a population-based cohort of people with diabetes, the aims of the analysis reported here were: (1) to investigate the association between plasma lipids, lipoprotein lipids and apolipoprotein with mortality from cardiovascular disease; and (2) to assess whether age modifies any of these relationships.

\section{Subjects and methods}

The study population comprised 1,565 patients with known type 2 diabetes who were resident in 1988 in the town of Casale Monferrato in north-west Italy (93,477 inhabitants). These individuals were invited to undergo a baseline examination in 1991-1992 to assess the prevalence of micro- and macroalbuminuria and cardiovascular risk factors and were followed up to 31 December 2001 [22].
Participants were identified from a diabetes clinic, general practitioners (23.8\% of the cohort), hospital discharge records, prescriptions, and records of sales of reagent strips and syringes. A high degree of ascertainment was achieved (80\%) [25]. Surveys conducted in Italy showed that the participants were representative of patients with diabetes in the country with regard to age, sex, duration of diabetes, BMI and type of antidiabetic treatment [26].

As described in detail elsewhere, all patients were interviewed and examined by trained investigators at baseline [22]. All individuals gave informed consent and the study was carried out in accordance with the Declaration of Helsinki. Hypertension was defined as systolic blood pressure $\geq 140 \mathrm{mmHg}$ or diastolic blood pressure $\geq 90 \mathrm{mmHg}$ or treatment with antihypertensive drugs. Venous blood samples were collected after fasting for determination of triglycerides, total cholesterol, HDLcholesterol (enzymatic colorimetric method after precipitation with $\mathrm{Mn}^{2+}$ ), ApoA-I, ApoB (turbidimetric method; BM/Hitachi 717, BBR, Tokyo, Japan) and $\mathrm{HbA}_{1 \mathrm{c}}$ (HPLC; Daiichi, Menarini, Japan; laboratory reference range 3.85.5\%). LDL-cholesterol was calculated from Friedewald's formula for all except 44 people in the cohort who had triglycerides $>4.48 \mathrm{mmol} / \mathrm{l}(400 \mathrm{mg} / \mathrm{dl})$. All laboratory determinations were centralised. The albumin excretion rate (AER) was calculated on the basis of the urinary albumin concentration, measured in a single, timed, overnight urine sample, analysed by the nephelometric method (Behring Nephelometer Analyzer, Behring Institute, Marburg, Germany), after exclusion of urinary tract infection, congestive heart failure and other known causes of non-diabetic renal disease. Smoking was classified into: never, ex-smoker if the patient had stopped smoking at least 1 month before the visit, and smoker. For all patients enrolled, the date of diagnosis was recorded. CHD was defined from ECG abnormalities according to the Minnesota code, as described previously [27].

During the follow-up period (1991-2001), the participants were examined regularly during routine clinical practice, three or four times per year, either at the diabetes clinic or by general practitioners, with centralised measurements of $\mathrm{HbA}_{1 \mathrm{c}}$. The average cumulative individual concentrations of $\mathrm{HbA}_{1 \mathrm{c}}$ during follow-up were calculated.

The relevant time scale for the analysis was time since diagnosis of diabetes to death or to 31 December 2001, whichever came first. Information on deaths was obtained from the demographic files of towns of residence and hospital discharge and autopsy records. Only one patient was lost to follow-up. The underlying causes of death were derived and coded by two of the authors according to the ninth revision of the International Classification of Diseases (ICD). Mortality rates were calculated by dividing the number of deaths that occurred during the study period by the number of person-years of observation.

All continuous variables were categorised into quartiles of their distribution, except for age, which was categorised into 5-year age groups $(<60,60-64,65-69,70-74,75-79$, $>79$ years). The excess of risk of death from cardiovascular disease and from all causes due to lipids, lipoprotein lipids 
and lipoprotein was expressed by hazard ratios (HR). Ageand sex-adjusted HRs were calculated by multivariate Cox proportional hazards modelling. Models included conventional risk factors (age, sex, smoking, hypertension, CHD), novel risk factors (AER, fibrinogen) and cumulative individual average $\mathrm{HbA}_{1 \mathrm{c}}$ during follow-up (time-dependent variable). The HRs were also adjusted for referring physician, as previous analyses of the Casale Monferrato cohort identified this as a significant predictor of mortality [24]. Given the time scale, all the models were also adjusted for known duration of diabetes. We tested for linear trends across categorical variables by entering a single ordinal term into the Cox regression model. The proportional hazard assumptions of explanatory variables were assessed on the basis of Schoenfeld residuals. We tested for the effect of age on lipids by including interaction terms in the models. The likelihood ratio test was used to assess the significance of variables. The $p$ value was twosided; $p<0.05$ was considered to indicate statistical significance. All analyses were performed with Stata (Release 8.0, 2002; Stata, College Station, TX, USA).

\section{Results}

The baseline cohort comprised mainly older people (mean age $68.7 \pm 10.7$ years). Patients treated exclusively by general practitioners constituted $23.8 \%$ of the cohort. The median value for plasma LDL-cholesterol was $3.52 \mathrm{mmol} / 1$ $(136 \mathrm{mg} / \mathrm{dl})$, and only $28.5 \%$ of patients had values $>4.14 \mathrm{mmol} / 1(160 \mathrm{mg} / \mathrm{dl})$. A small minority $(5.4 \%)$ was being treated for hyperlipidaemia. As shown in Table 1, the prevalence at the baseline examination of hypertension, $\mathrm{CHD}$ and macroalbuminuria, lower $\mathrm{BMI}$, plasma $\mathrm{HbA}_{1 \mathrm{c}}$, total cholesterol, LDL-cholesterol and triglycerides values and higher plasma concentrations of fibrinogen and HDLcholesterol was significantly higher in people aged $\geq 70$ years than in those aged $\leq 70$ years. No differences between age groups were found in the mean values of ApoA-I and ApoB. The prevalence of overweight (BMI $\left.26-29 \mathrm{~kg} / \mathrm{m}^{2}\right)$ and obesity $\left(\mathrm{BMI}>29 \mathrm{~kg} / \mathrm{m}^{2}\right)$ were 34.3 and $30.2 \%$ in people aged $\leq 70$ years and 29.0 and $18.2 \%$ in those aged $\geq 70$ years, respectively $(p<0.0001)$.

During the 11-year follow-up, 341 of 685 deaths were due to cardiovascular disease (ICD-9 codes 390-459) in 10,809 person-years of observation, giving a mortality rate for this cause of 31.5/1,000 person-years $(95 \%$ CI $28.4-35.1)$ and a rate for all causes of $63.4 / 1,000$ person-years (95\% CI 58.8 68.3). Table 2 shows the HRs for mortality from cardiovascular disease according to plasma lipid profile, after adjustment for age and sex (model 1), classical risk factors (hypertension, smoking, CHD), novel risk factors (AER, fibrinogen), cumulative average $\mathrm{HbA}_{1 \mathrm{c}}$ during follow-up and referring physician (model 2). Further adjustment for non-HDL-cholesterol was performed in model 3.

Table 1 Characteristics of subjects with type 2 diabetes by age at baseline examination (1991-1992)

\begin{tabular}{|c|c|c|c|c|}
\hline Characteristic & Whole cohort $(n=1,565)$ & Aged $\leq 70$ years $(n=850)$ & Aged $>70$ years $(n=715)$ & $p$ value $^{\mathrm{a}}$ \\
\hline Age (years) & $68.7 \pm 10.7$ & $60.7 \pm 7.0$ & $78.1 \pm 5.3$ & $<0.0001$ \\
\hline Men $(\%)$ & $679(43.4 \%)$ & $424(49.9 \%)$ & $255(35.7 \%)$ & $<0.0001$ \\
\hline Duration of diabetes (years) & $10.8 \pm 7.0$ & $9.9 \pm 6.2$ & $11.9 \pm 7.7$ & $<0.0001$ \\
\hline BMI $\left(\mathrm{kg} / \mathrm{m}^{2}\right)$ & $27.3 \pm 4.6$ & $28.0 \pm 4.8$ & $26.3 \pm 4.3$ & $<0.0001$ \\
\hline Hypertension (\%) & $1,309(84.5 \%)$ & $694(82.0 \%)$ & $615(87.5 \%)$ & 0.003 \\
\hline $\mathrm{CHD}$ & $24.4 \%$ & $22.0 \%$ & $27.3 \%$ & 0.02 \\
\hline \multicolumn{5}{|l|}{$\operatorname{AER}(\mu \mathrm{g} / \mathrm{min})$} \\
\hline$<20$ & $762(50.3 \%)$ & $441(53.5 \%)$ & $321(46.6 \%)$ & \multirow[t]{3}{*}{0.05} \\
\hline $20-200$ & $483(31.9 \%)$ & $259(31.4 \%)$ & $224(32.5 \%)$ & \\
\hline$>200$ & $222(18.7 \%)$ & $125(15.1 \%)$ & $144(20.9 \%)$ & \\
\hline Cared for by general practitioner (\%) & $369(23.7 \%)$ & $159(18.8 \%)$ & $210(29.6 \%)$ & $<0.0001$ \\
\hline \multicolumn{5}{|l|}{ Treatment } \\
\hline Diet & $188(12.2 \%)$ & $90(10.6 \%)$ & $98(14.0 \%)$ & \multirow[t]{3}{*}{0.11} \\
\hline Oral hypoglycaemics & $1,096(70.9 \%)$ & $604(71.6 \%)$ & $492(70.2 \%)$ & \\
\hline Insulin & $261(16.9 \%)$ & $150(17.8 \%)$ & $111(15.8 \%)$ & \\
\hline Fibrinogen (g/l) & $3.6 \pm 0.9$ & $3.6 \pm 0.9$ & $3.7 \pm 0.9$ & 0.008 \\
\hline $\mathrm{HbA}_{1 \mathrm{c}}(\%)$ & $8.0 \pm 2.3$ & $8.3 \pm 2.4$ & $7.7 \pm 2.1$ & $<0.0001$ \\
\hline Total cholesterol (mmol/l) & $5.79 \pm 1.26$ & $5.89 \pm 1.30$ & $5.67 \pm 1.20$ & 0.008 \\
\hline LDL-cholesterol (mmol/l) & $3.60 \pm 1.09$ & $3.68 \pm 1.12$ & $3.50 \pm 1.05$ & 0.01 \\
\hline HDL-cholesterol (mmol/l) & $1.41 \pm 0.42$ & $1.39 \pm 0.42$ & $1.44 \pm 0.41$ & 0.04 \\
\hline Triglycerides $(\mathrm{mmol} / \mathrm{l})^{\mathrm{b}}$ & $1.52(1.06-2.05)$ & $1.50(1.09-2.09)$ & $1.37(1.03-1.89)$ & 0.003 \\
\hline ApoA-I (mg/dl) & $134.8 \pm 34.5$ & $134.5 \pm 34.7$ & $135.1 \pm 34.4$ & 0.72 \\
\hline ApoB (mg/dl) & $104.3 \pm 37.4$ & $104.5 \pm 37.9$ & $104.1 \pm 36.8$ & 0.84 \\
\hline
\end{tabular}

${ }^{\mathrm{a}}$ For comparison between age groups

${ }^{\mathrm{b}}$ Geometric mean (interquartile range) 
Table 2 Mortality rates from cardiovascular disease in subjects of the study cohort with type 2 diabetes, classified by plasma lipid concentrations at baseline examination (1991-1992)

\begin{tabular}{lllll}
\hline Plasma lipid & Mortality rate from cardiovascular disease & $\mathrm{HR}^{\mathrm{a}}(95 \% \mathrm{CI})$ & $\mathrm{HR}^{\mathrm{b}}(95 \% \mathrm{CI}) \quad \mathrm{HR}$ & $(95 \% \mathrm{CI})$
\end{tabular} (death rate/1,000 person-years)

\begin{tabular}{|c|c|c|c|c|c|}
\hline \multicolumn{6}{|c|}{ Total cholesterol (mmol/l) } \\
\hline$<4.91$ & 87 & 36.6 & 1.00 & \multicolumn{2}{|l|}{1.00} \\
\hline $4.91-5.69$ & 88 & 32.3 & $0.89(0.66-1.20)$ & \multicolumn{2}{|l|}{$0.83(0.59-1.18)$} \\
\hline $5.70-6.49$ & 83 & 29.3 & $0.80(0.59-1.09)$ & \multicolumn{2}{|l|}{$0.80(0.56-1.14)$} \\
\hline$>6.49$ & 73 & 25.9 & $0.78(0.57-1.08)$ & \multicolumn{2}{|l|}{$0.67(0.46-0.99)$} \\
\hline$p$ for trend & & & 0.11 & \multicolumn{2}{|l|}{0.05} \\
\hline \multicolumn{6}{|c|}{ LDL-cholesterol (mmol/l) } \\
\hline$<2.89$ & 82 & 34.0 & 1.00 & \multicolumn{2}{|l|}{1.00} \\
\hline $2.89-3.53$ & 84 & 32.2 & $0.96(0.71-1.31)$ & \multicolumn{2}{|l|}{$0.90(0.63-1.28)$} \\
\hline $3.54-4.29$ & 79 & 28.5 & $0.92(0.67-1.25)$ & \multicolumn{2}{|l|}{$0.91(0.63-1.29)$} \\
\hline$>4.29$ & 70 & 26.7 & $0.91(0.66-1.27)$ & \multicolumn{2}{|l|}{$0.77(0.53-1.12)$} \\
\hline$p$ for trend & & & 0.49 & \multicolumn{2}{|l|}{0.20} \\
\hline \multicolumn{6}{|c|}{ HDL-cholesterol (mmol/l) } \\
\hline$<1.16$ & 104 & 39.0 & 1.00 & \multicolumn{2}{|l|}{1.00} \\
\hline $1.16-1.37$ & 76 & 27.4 & $0.67(0.50-0.90)$ & \multicolumn{2}{|l|}{$0.79(0.56-1.11)$} \\
\hline $1.38-1.63$ & 75 & 28.7 & $0.67(0.49-0.90)$ & \multicolumn{2}{|l|}{$0.64(0.45-0.92)$} \\
\hline$>1.63$ & 70 & 26.4 & $0.55(0.41-0.75)$ & \multicolumn{2}{|l|}{$0.66(0.47-0.95)$} \\
\hline$p$ for trend & & & 0.0003 & \multicolumn{2}{|l|}{0.01} \\
\hline \multicolumn{6}{|c|}{ Non-HDL-cholesterol (mmol/l) } \\
\hline$<3.57$ & 86 & 33.5 & 1.00 & \multicolumn{2}{|l|}{1.00} \\
\hline $3.57-4.25$ & 81 & 31.7 & $0.96(0.71-1.31)$ & $0.87(0.61-1.24)$ & \\
\hline $4.26-5.12$ & 81 & 28.3 & $0.93(0.68-1.27)$ & $0.96(0.68-1.35)$ & \\
\hline$>5.12$ & 77 & 28.4 & $1.03(0.75-1.41)$ & $0.79(0.54-1.15)$ & \\
\hline$p$ for trend & & & 0.99 & 0.32 & \\
\hline LDL:HDL ( & & & & & \\
\hline$<1.98$ & 70 & 26.4 & 1.00 & 1.00 & \\
\hline $1.98-2.56$ & 76 & 29.6 & $1.12(0.81-1.56)$ & $1.00(0.68-1.46)$ & \\
\hline $2.57-3.34$ & 84 & 31.8 & $1.37(1.00-1.88)$ & $1.26(0.87-1.82)$ & \\
\hline$>3.34$ & 85 & 33.1 & $1.60(1.16-2.20)$ & $1.25(0.86-0.81)$ & \\
\hline$p$ for trend & & & 0.003 & 0.13 & \\
\hline Triglycerides & & & & & \\
\hline$<1.06$ & 84 & 32.4 & 1.00 & 1.00 & 1.00 \\
\hline $1.06-1.43$ & 74 & 27.4 & $0.89(0.65-0.23)$ & $0.85(0.59-1.23)$ & $0.86(0.59-1.24)$ \\
\hline $1.44-2.03$ & 88 & 32.6 & $1.17(0.87-1.58)$ & $0.94(0.66-1.35)$ & $0.98(0.68-1.41)$ \\
\hline$>2.03$ & 84 & 30.7 & $1.09(0.80-1.49)$ & $0.89(0.62-1.28)$ & $0.96(0.65-1.42)$ \\
\hline$p$ for trend & & & 0.98 & 0.70 & 0.99 \\
\hline ApoA-I (mg & & & & & \\
\hline$<111$ & 91 & 34.6 & 1.00 & 1.00 & 1.00 \\
\hline $112-129$ & 88 & 32.9 & $0.99(0.74-1.33)$ & $0.99(0.70-1.39)$ & $0.99(0.70-1.40)$ \\
\hline $130-152$ & 73 & 28.1 & $0.72(0.52-0.98)$ & $0.82(0.57-1.18)$ & $0.83(0.58-1.19)$ \\
\hline$>152$ & 68 & 24.5 & $0.65(0.47-0.90)$ & $0.78(0.55-1.12)$ & $0.79(0.55-1.12)$ \\
\hline$p$ for trend & & & 0.002 & 0.12 & 0.13 \\
\hline ApoB $(\mathrm{mg} / \mathrm{d}$ & & & & & \\
\hline$<77$ & 76 & 26.9 & 1.00 & 1.00 & 1.00 \\
\hline $77-101$ & 68 & 24.5 & $0.99(0.72-1.39)$ & $1.12(0.75-1.67)$ & $1.24(0.82-1.88)$ \\
\hline $102-126$ & 88 & 34.8 & $1.44(1.05-1.96)$ & $1.59(1.10-2.29)$ & $1.80(1.22-2.64)$ \\
\hline$>126$ & 88 & 34.6 & $1.30(0.96-1.78)$ & $1.48(1.02-2.14)$ & $1.77(1.18-2.66)$ \\
\hline$p$ for trend & & & 0.034 & 0.012 & 0.001 \\
\hline ApoB:ApoA & & & & & \\
\hline$<0.58$ & 66 & 25.3 & 1.10 & 1.00 & 1.00 \\
\hline $0.58-0.76$ & 69 & 22.9 & $1.14(0.81-1.61)$ & $1.09(0.74(1.63)$ & $1.22(0.81-1.84)$ \\
\hline $0.77-0.96$ & 88 & 34.4 & $1.59(1.15-2.20)$ & $1.59(1.09-2.33)$ & $1.84(1.23-2.74)$ \\
\hline
\end{tabular}


Table 2 (continued)

\begin{tabular}{|c|c|c|c|c|c|}
\hline Plasma lipid & & $\begin{array}{l}\text { rdiovascular disease } \\
\text { on-years) }\end{array}$ & $\mathrm{HR}^{\mathrm{a}}(95 \% \mathrm{CI})$ & $\mathrm{HR}^{\mathrm{b}}(95 \% \mathrm{CI})$ & $\operatorname{HR}^{\mathrm{c}}(95 \% \mathrm{CI})$ \\
\hline $\begin{array}{l}>0.96 \\
p \text { for trend }\end{array}$ & 97 & 39.0 & $\begin{array}{l}1.86(1.36-2.56) \\
<0.0001\end{array}$ & $\begin{array}{l}1.69(1.16-2.46) \\
0.001\end{array}$ & $\begin{array}{l}2.06(1.36-3.11) \\
<0.0001\end{array}$ \\
\hline
\end{tabular}

${ }^{\mathrm{a}}$ Adjusted for age and sex

${ }^{\mathrm{b}}$ Adjusted for age, sex, hypertension, smoking, CHD, AER, fibrinogen, cumulative average individual $\mathrm{Hb}_{1 \mathrm{c}}$ and referring physician

${ }^{c}$ Adjusted for the above ( $\left.{ }^{b}\right)$ and non-HDL-cholesterol

Decreasing trends in HRs adjusted for multiple factors were found across quartiles of total cholesterol, LDLcholesterol and non-HDL-cholesterol; statistical significance was reached only for total cholesterol, with HRs for the upper vs the lower quartile of 0.67 (95\% CI 0.46-0.99, $p$ for trend $=0.05$ ) for mortality from cardiovascular disease and $0.60(95 \%$ CI $0.46-0.79, p$ for trend $<0.0001)$ for mortality from all causes. The HRs were similar with regard to non-HDL-cholesterol: 0.79 (95\% CI 0.54-1.15, $p$ for trend $=0.32$ ) for mortality from cardiovascular disease and $0.70(95 \%$ CI $0.54-0.91, p$ for trend $=0.004)$ for mortality from all causes. Decreasing trends across quartiles of HDL-cholesterol $(p=0.01$ and $p=0.003$, model 2) and ApoA-I ( $p=0.13$ and $p=0.03$, model 3) were also found for mortality from both cardiovascular disease and all causes, respectively. A significant rising trend in age- and sex-adjusted HRs for mortality from cardiovascular disease was found across quartiles of the LDL-cholesterol:HDL-cholesterol ratio (model 1, $p=0.003$ ), whereas in the model with adjustment for multiple factors, the HR for the upper quartile decreased from 1.60 to 1.25 ( $p$ for trend $=0.13$ ). No associations were found between triglycerides concentrations and mortality from either cardiovascular disease or all causes.

ApoB and non-HDL-cholesterol concentrations were highly correlated $(r=0.49, p<0.0001)$. Nevertheless, their association with the outcome was markedly different in multivariate analyses. An increasing trend of adjusted HRs was seen across ApoB quartiles ( $p=0.012$, model 2$)$, with values of 1.59 (95\% CI 1.10-2.92) and 1.48 (95\% CI $1.02-$ 2.14 ) for the upper vs the lower quartile. The finding that the HR in the fourth quartile was lower than that in the third is probably due to survival bias, as at baseline we recruited a cohort of people with prevalent rather than incident diabetes. Whereas the HRs for other lipids were virtually unchanged by adjustment for cumulative $\mathrm{HbA}_{1 \mathrm{c}}$ during follow-up, the HRs for ApoB appeared to be negatively confounded by glycaemic control, as the HR increased in the upper quartiles, from 1.47 to 1.59 and from 1.35 to 1.48 , after further adjustment for cumulative individual $\mathrm{HbA}_{1 \mathrm{c}}$. The association of $\mathrm{ApoB}$ with mortality from cardiovascular disease was seen even after adjustment for non-HDL-cholesterol: HR=1.80 (95\% CI 1.22-2.64) for the third quartile and 1.77 (95\% CI 1.18-2.66) for the fourth quartile ( $p$ for trend $=0.001$, model 3). ApoB had no association with mortality from all causes $(\mathrm{HR}=1.03 ; 95 \%$ CI $0.79-1.34$ for the upper quartile). As shown in Table 2, the highest mortality risk was seen for ApoB:ApoA-I $(\mathrm{HR}=1.59$ [95\% CI 1.09-2.33] for the third quartile, and 1.69 [95\% CI 1.16-2.46] for the fourth quartile; $p$ for trend $=0.001$, model 2 ); after adjustment for non-HDLcholesterol, further increases in HR were seen $(\mathrm{HR}=1.84$ [95\% CI 1.23-2.74] and HR=2.06 [95\% CI 1.36-3.11]; $p$ for trend $<0.0001$, model 3 ).

As the interaction terms with age were significant, we stratified our analyses by age at baseline examination $(\leq 70$ vs $>70$ years) (Tables 3 and 4). In general, most changes in risk were seen in people $>70$ years; however, even in those $>70$ years, ApoB and ApoB:ApoA-I were independently associated with mortality after adjustment for non-HDLcholesterol. In this analysis, the apparent protective effect of non-HDL-cholesterol on mortality from cardiovascular disease was seen only in the oldest age group. The HRs for the upper quartiles were $1.52(95 \%$ CI $0.72-3.23, p$ for trend $=0.25)$ for people $\leq 70$ years and $0.58(95 \%$ CI 0.36 $0.93, p$ for trend $=0.03)$ for those $>70$ years. The respective values for ApoB (model 3) were 2.86 (95\% CI 1.22-6.67, $p$ for trend $=0.005)$ and $1.50(95 \%$ CI $0.93-2.41, p$ for trend $=0.04)$. The ApoB:ApoA-I ratio was negatively confounded by non-HDL-cholesterol in older people, as shown by significant association in higher quartiles after adjustment for non-HDL-cholesterol: HR=1.94 (95\% CI $1.20-3.13, p$ for trend $=0.003$ ).

The estimated HRs were not modified by further adjustment for treatment of diabetes or hyperlipidaemia (5.4\% of the cohort), for BMI, or for exclusion of people who died within 1 year of follow-up.

\section{Discussion}

In this population-based cohort of patients with type 2 diabetes in a Mediterranean country, who have a lower risk of cardiovascular disease than people living in northern Europe and the USA, ApoB and the ApoB:ApoA-I ratio were associated with mortality from cardiovascular disease independently of non-HDL-cholesterol. These associations were seen in people $<70$ years of age and were independent of classical cardiovascular risk factors (sex, smoking, hypertension, CHD), novel risk factors (AER, fibrinogen) and individual average cumulative $\mathrm{HbA}_{1 \mathrm{c}}$ during followup. In people aged $>70$ years, ApoB and ApoB:ApoA-I were still associated with mortality from cardiovascular disease, but more weakly than for people aged $\leq 70$ years. 
Table 3 HRs for mortality from cardiovascular disease in subjects of the study cohort with type 2 diabetes, classified by age at baseline examination and plasma lipid concentrations

\begin{tabular}{|c|c|c|}
\hline Plasma lipid & $\begin{array}{l}\text { Age } \leq 70 \text { years } \\
\operatorname{HR}^{\mathrm{a}}(95 \% \mathrm{CI})\end{array}$ & $\begin{array}{l}\text { Age }>70 \text { years } \\
\operatorname{HR}^{\mathrm{a}}(95 \% \mathrm{CI})\end{array}$ \\
\hline \multicolumn{3}{|c|}{ Total cholesterol $(\mathrm{mmol} / \mathrm{l})$} \\
\hline$<4.91$ & 1.00 & 1.00 \\
\hline $4.91-5.69$ & $0.74(0.33-1.67)$ & $0.87(0.58-1.29)$ \\
\hline $5.70-6.49$ & $1.32(0.67-2.62)$ & $0.60(0.39-0.91)$ \\
\hline$>6.49$ & $0.99(0.49-2.02)$ & $0.55(0.34-0.88)$ \\
\hline$p$ for trend & 0.66 & 0.003 \\
\hline \multicolumn{3}{|c|}{ LDL-cholesterol (mmol/l) } \\
\hline$<2.89$ & 1.00 & 1.00 \\
\hline $2.89-3.53$ & $0.71(0.31-1.63)$ & $0.96(0.64-1.42)$ \\
\hline $3.54-4.29$ & $1.00(0.49-2.06)$ & $0.84(0.56-1.28)$ \\
\hline$>4.29$ & $1.03(0.52-2.08)$ & $0.59(0.38-0.95)$ \\
\hline$p$ for trend ${ }^{\mathrm{b}}$ & 0.70 & 0.03 \\
\hline \multicolumn{3}{|c|}{ HDL-cholesterol (mmol/l) } \\
\hline$<1.16$ & 1.00 & 1.00 \\
\hline $1.16-1.37$ & $0.62(0.32-1.22)$ & $0.91(0.61-1.37)$ \\
\hline $1.38-1.63$ & $0.74(0.39-1.40)$ & $0.58(0.37-0.90)$ \\
\hline$>1.63$ & $0.71(0.34-1.49)$ & $0.64(0.42-0.96)$ \\
\hline$p$ for trend & 0.35 & 0.009 \\
\hline \multicolumn{3}{|c|}{$\begin{array}{l}\text { Non-HDL-cholesterol } \\
(\mathrm{mmol} / \mathrm{l})\end{array}$} \\
\hline$<3.57$ & 1.00 & 1.00 \\
\hline $3.57-4.25$ & $1.25(0.54-2.87)$ & $0.80(0.53-1.19)$ \\
\hline $4.26-5.12$ & $1.47(0.69-3.12)$ & $0.80(0.54-1.19)$ \\
\hline$>5.12$ & $1.52(0.72-3.23)$ & $0.58(0.36-0.93)$ \\
\hline$p$ for trend & 0.25 & 0.03 \\
\hline \multicolumn{3}{|c|}{ LDL:HDL (mmol/l) } \\
\hline$<1.98$ & 1.00 & 1.00 \\
\hline $1.98-2.56$ & $1.65(0.73-3.73)$ & $0.86(0.55-1.34)$ \\
\hline $2.57-3.34$ & $1.48(0.64-3.40)$ & $1.26(0.83-1.91)$ \\
\hline$>3.34$ & $1.29(0.57-2.97)$ & $1.29(0.84-1.98)$ \\
\hline$p$ for trend & 0.80 & 0.11 \\
\hline \multicolumn{3}{|c|}{ Triglycerides (mmol/l) } \\
\hline$<1.06$ & 1.00 & 1.00 \\
\hline $1.06-1.43$ & $0.75(0.34-1.64)$ & $0.87(0.57-1.32)$ \\
\hline $1.44-2.03$ & $0.68(0.32-1.45)$ & $1.08(0.72-1.12)$ \\
\hline$>2.03$ & $1.24(0.63-2.44)$ & $0.77(0.49-1.20)$ \\
\hline$p$ for trend & 0.39 & 0.46 \\
\hline
\end{tabular}

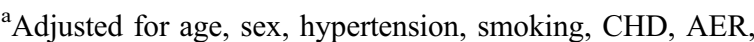
fibrinogen, cumulative average individual $\mathrm{HbA}_{1 \mathrm{c}}$ and referring physician

Non-HDL-cholesterol appeared to have a protective effect against mortality from all causes and from cardiovascular disease. In contrast, a decreasing trend in mortality risk was seen with increasing plasma values of HDL-cholesterol in both age groups.

Ours is the first population-based study conducted to compare ApoB and non-HDL-cholesterol values in white people of European origin with diabetes. The Strong Heart Study, which addressed only American Indians, showed that non-HDL-cholesterol is a better predictor of cardiovascular morbidity than LDL-cholesterol [17]. Two further studies of people with diabetes in the USA, who were free of cardiovascular disease at baseline, comprised 921 female nurses aged $<65$ years [18] and 746 male health professionals aged 46-81 years [19]. In both studies, nonHDL-cholesterol was considered a better predictor of cardiovascular disease than ApoB. In contrast, the AMORIS study of more than 170,000 people in Sweden indicated that ApoB and ApoA-I are better predictors than lipoprotein lipids overall and are of greatest value in predicting CHD in people with normal or low LDLcholesterol values and in the elderly [11].

Although the previous studies were well conducted and analysed, their results cannot be extrapolated to Mediterranean populations, who are characterised by a lower risk of cardiovascular disease, attributed mainly to the Mediterranean diet. Furthermore, people with diabetes in this population have lower excess mortality from cardiovascular disease than the general population (standardised mortality ratio 1.42 in the Verona Diabetes Study and 1.35 in the Casale Monferrato Study) $[20,21]$ and are older at onset of the disease, with a median age of 70 years in Italian cohorts of prevalent cases. The Casale Monferrato cohort is representative of Italian patients with diabetes as regards age, sex, duration of disease, BMI and type of antidiabetic treatment [26]. Moreover, we recruited a population-based cohort of patients with diabetes and could therefore take into account differences between patients cared for exclusively by general practitioners and those treated in diabetes clinics [28]. Other strengths of the present study are the completeness of ascertainment of the cohort, centralised measurements and long follow-up for survival, resulting in 6,837 person-years of observation for people aged $\leq 70$ years and 3,972 person-years for those aged $\geq 70$ years.

Our study adds to knowledge about the relationship between lipids, lipoproteins and cardiovascular risk, demonstrating an association of ApoB and ApoB:ApoA-I in Mediterranean people with diabetes. ApoB predicts mortality from cardiovascular disease even in the presence of normal or low non-HDL-cholesterol values. A detailed study has shown that measurements of $A$ poB provide a better estimate of small dense LDL particles, which are not detected by simple measurement of non-HDL-cholesterol [14]. Our findings are therefore consistent with those of others [8].

There is increasing evidence that the relationship between traditional risk factors and cardiovascular disease changes with advancing age. Whereas low HDL-cholesterol is predictive of cardiovascular disease even among people $>70$ years old $[29,30]$, observational studies in the elderly have either shown no predictive effect of plasma LDL-cholesterol or a protective effect of higher concentrations [3-6]. In a large population-based cohort of elderly people in the USA, $20 \%$ of whom had diabetes, the protective effect of higher concentrations of total choles- 
Table 4 HRs for mortality from cardiovascular disease in subjects of the study cohort with type 2 diabetes, classified by age at baseline examination and plasma apolipoprotein concentrations

\begin{tabular}{|c|c|c|c|c|}
\hline \multirow[t]{2}{*}{ Plasma apolipoprotein } & \multicolumn{2}{|l|}{ Age $\leq 70$ years } & \multicolumn{2}{|l|}{ Age $>70$ years } \\
\hline & $\operatorname{HR}^{\mathrm{a}}(95 \% \mathrm{CI})$ & $\mathrm{HR}^{\mathrm{b}}(95 \% \mathrm{CI})$ & $\mathrm{HR}^{\mathrm{a}}(95 \% \mathrm{CI})$ & $\mathrm{HR}^{\mathrm{b}}(95 \% \mathrm{CI})$ \\
\hline \multicolumn{5}{|l|}{ ApoA-I (mg/dl) } \\
\hline $112-129$ & $0.64(0.34-1.20)$ & $0.63(0.34-1.19)$ & $1.16(0.77-1.77)$ & $1.18(0.77-1.79)$ \\
\hline $130-152$ & $1.08(0.55-2.13)$ & $1.09(0.55-2.16)$ & $0.75(0.48-1.17)$ & $0.74(0.48-1.15)$ \\
\hline \multicolumn{5}{|l|}{ ApoB (mg/dl) } \\
\hline$<77$ & 1.00 & 1.00 & 1.00 & 1.00 \\
\hline $77-101$ & $1.40(0.63-3.13)$ & $1.33(0.56-3.15)$ & $1.03(0.65-1.65)$ & $1.18(0.73-1.91)$ \\
\hline $102-126$ & $1.96(0.89-4.32)$ & $1.94(0.84-4.49)$ & $1.44(0.94-2.21)$ & $1.69(1.08-2.63)$ \\
\hline$>126$ & $2.92(1.34-6.37)$ & $2.86(1.22-6.67)$ & $1.15(0.75-1.77)$ & $1.50(0.93-2.41)$ \\
\hline $0.77-0.96$ & $2.06(0.81-5.25)$ & $1.99(0.76-5.18)$ & $1.50(0.98-2.29)$ & $1.85(1.18-2.90)$ \\
\hline$>0.96$ & $3.06(1.23-7.62)$ & $2.98(1.15-7.75)$ & $1.42(0.92-2.19)$ & $1.94(1.20-3.13)$ \\
\hline$p$ for trend & 0.006 & 0.009 & 0.05 & 0.003 \\
\hline
\end{tabular}

${ }^{\mathrm{a}}$ Adjusted for age, sex, hypertension, smoking, CHD, AER, fibrinogen, cumulative average individual $\mathrm{HbA}_{1 \mathrm{c}}$ and referring physician

${ }^{\mathrm{b}}$ Adjusted for the above $\left({ }^{\mathrm{a}}\right)$ and non-HDL-cholesterol

terol disappeared after adjustment for markers of poor health, suggesting confounding effects of comorbidity and frailty [5]. In the Honolulu Heart Program, in which 3,572 Japanese American men were followed-up prospectively for 20 years, significantly decreasing age-adjusted mortality rates were found for the upper vs the lower quartiles of cholesterol concentrations, particularly in men with persistently low cholesterol values in consecutive examinations [3]. Our results are therefore consistent with those of other observational studies, including the AMORIS study [11], showing lower predictive power of cholesterol levels on cardiovascular events in the elderly than in younger age groups. From a practical point of view, however, trials have shown that even the elderly benefit greatly from treatment to reduce high cholesterol concentrations: this treatment should be prescribed in elderly diabetic people with hypercholesterolaemia [2]. Our findings could be due, at least in part, to the effect of frailty and comorbidities. However, neither adjusting for BMI nor the removing of the deaths that occurred within the first year of follow-up modified our results.

In conclusion, the results of this population-based study indicate that in people living in the Mediterranean region who have diabetes, ApoB and ApoB:ApoA-I are associated with mortality from cardiovascular disease independently of non-HDL-cholesterol. Our findings support the recommendation that measurement of ApoB and ApoA-I should be added to the lipid profile assessment of people with diabetes, particularly for the elderly, for whom predictions based only on total cholesterol and non-HDLcholesterol values could be misleading. Elderly people with diabetes and high concentrations of ApoB and ApoB:
ApoA-I should be considered at high risk, even if their LDL-cholesterol values are low or normal.

Acknowledgements We thank the patients, the nurses at the diabetes clinic, the diabetologists and the general practitioners for long-standing collaboration in this study. We would like to thank A. D. Sniderman for his useful advice. The Casale Monferrato Study is supported by grants from the Ministry of Education, University and Scientific and Technologic Research, Italy. We also acknowledge the contribution of the Italian Association for Cancer Research and the Compagnia San Paolo/FIRMS.

\section{References}

1. Grundy SM, Cleeman JI, Merz CN et al (2004) Implications of recent clinical trials for the National Cholesterol Education Program Adult Treatment Panel III Guidelines. J Am Coll Cardiol 44:720-732

2. Dornbrook-Lavender KA, Pieper JA, Roth MT (2003) Primary prevention of coronary heart disease in the elderly. Ann Pharmacother 37:1654-1663

3. Schatz IJ, Masaki K, Yano K, Chen R, Rodriguez BL, Curb JD (2001) Cholesterol and all-cause mortality in elderly people from the Honolulu heart program. A cohort study. Lancet 358:351-355

4. Fried L, Kronmal RA, Newman AB et al (1998) Risk factors for 5-year mortality in older adults. The Cardiovascular Health Study. JAMA 279:585-592

5. Corti MC, Guralnik JM, Salive ME et al (1997) Clarifying the direct relation between total cholesterol levels and death from coronary heart disease in older persons. Ann Intern Med 126:753-760

6. Krumholz HM, Seeman TE, Merrill SS et al (1994) Lack of association between cholesterol and coronary heart disease mortality and morbidity and all-cause mortality in persons older than 70 years. JAMA 272:1335-1340 
7. Dornbrook-Lavender KA, Pieper JA, Roth MT (2003) Primary prevention of coronary heart disease in the elderly. Ann Pharmacother 37:1654-1663

8. Sniderman AD (2002) How, when, and why to use apolipoprotein B in clinical practice. Am J Cardiol 90(Suppl):48i-54i

9. Sniderman AD, St-Pierre AC, Cantin B, Dagenais GR, Despres JP, Lamarche B (2003) Concordance/discordance between plasma apolipoprotein B levels and the cholesterol indexes of atherosclerotic risk. Am J Cardiol 91:1173-1177

10. Sniderman AD, Furberg CD, Keech A et al (2003) Apolipoproteins versus lipids as indices of coronary risk and as targets for statin treatment. Lancet 361:777-780

11. Walldius G, Jungner I, Holme I, Aastveit AH, Kolar W, Steiner E (2001) High apolipoprotein B, low apolipoprotein A-I, and improvement in the prediction of fatal myocardial infarction (AMORIS study): a prospective study. Lancet 358:2026-2033

12. Yusuf S, Hawken S, Ounpuu S et al (2004) Effect of potentially modifiable risk factors associated with myocardial infarction in 52 countries (the INTERHEART study): case-control study. Lancet 364:912-914

13. Sniderman AD (2003) Non-HDL cholesterol versus apolipoprotein B in diabetic dyslipoproteinemia: alternatives and surrogates versus the real thing. Diabetes Care 26:2207-2208

14. Wagner AM, Perez A, Zapico E, Ordonez-Llanos J (2003) NonHDL cholesterol and apolipoprotein B in the dyslipidemic classification of type 2 diabetic patients. Diabetes Care 26:2048-2051

15. Expert Panel on Detection, Evaluation, and Treatment of High Blood Cholesterol in Adults (Adult Treatment Panel III) (2001) Executive summary of the Third Report of the National Cholesterol Education Program (NCEP), Expert Panel on Detection, Evaluation, and Treatment of High Blood Cholesterol in Adults (Adult Treatment Panel III). JAMA 285: 2486-2497

16. Lehto S, Ronnemaa T, Haffner SM, Pyorala K, Kallio V, Laakso M (1997) Dyslipidemia and hyperglycemia predict coronary heart disease events in middle-aged patients with NIDDM. Diabetes 46:1354-1359

17. Lu W, Resnick HE, Jablonski KA et al (2003) Non-HDL cholesterol as a predictor of cardiovascular disease in type 2 diabetes: the Strong Heart Study. Diabetes Care 26:16-23

18. Schulze MB, Shai I, Manson JE et al (2004) Joint role of nonHDL cholesterol and glycated haemoglobin in predicting future coronary heart disease events among women with type 2 diabetes. Diabetologia 47:2129-2136
19. Jiang R, Schulze MB, Li T et al (2004) Non-HDL cholesterol and apolipoprotein B predict cardiovascular disease events among men with type 2 diabetes. Diabetes Care 27:1991-1997

20. Bruno G, Merletti F, Boffetta P et al (1999) Impact of glycaemic control, hypertension and insulin treatment on general and cause-specific mortality: an Italian populationbased cohort of type II (non-insulin-dependent) diabetes mellitus. Diabetologia 42:297-301

21. Brun E, Nelson RG, Bennett PH et al (2000) Verona Diabetes Study: diabetes duration and cause-specific mortality in the Verona Diabetes Study. Diabetes Care 23:1119-1123

22. Bruno G, Cavallo-Perin P, Bargero G et al (1996) Prevalence and risk factors for micro- and macroalbuminuria in an Italian population-based cohort of non-insulin-dependent diabetic subjects. Diabetes Care 19:43-47

23. Bruno G, Merletti F, Biggeri A et al (2005) Metabolic syndrome as predictor of all-causes and cardiovascular mortality in type 2 diabetes: the Casale Monferrato Study. Diabetes Care 27:2689-2694

24. Bruno G, Merletti F, Biggeri A et al (2005) Fibrinogen and albumin excretion rate are major independent predictors of 11 year cardiovascular mortality in type 2 diabetes: the Casale Monferrato Study. Diabetologia 48:427-434

25. Bruno G, LaPorte R, Merletti F, Biggeri A, McCarty D, Pagano G (1994) National diabetes programmes: application of capture-recapture to "count" diabetes? Diabetes Care 17: $548-556$

26. Garancini MP (1996) L'epidemiologia del diabete noninsulino-dipendente e della ridotta tolleranza al glucosio. In: Vaccaro O, Bonora E, Bruno O, Garancini MP, Muntoni S, Società Italiana di Diabetologia Gruppo di Studio di Epidemiologia e Statistica (eds) Il Diabete in Italia. Kurtis, Milan pp $17-30$

27. Veglio M, Bruno G, Borra M et al (2002) Prevalence of increased QT interval duration and dispersion in type 2 diabetic patients and its relationship with coronary heart disease: a population-based cohort. J Intern Med 251:317-324

28. Bruno G, Cavallo-Perin P, Bargero G et al (1999) Cardiovascular risk profile of type 2 diabetic patients cared for by general practitioners or by a diabetes clinic: a population-based study. J Clin Epidemiol 52:413-417

29. Curb JD, Abbott RD, Rodriguez BL et al (2004) High density lipoprotein cholesterol and the risk of stroke in elderly men. The Honolulu Heart Program. Am J Epidemiol 160:150-157

30. Corti MC, Guralnik JM, Salive ME et al (1995) HDL cholesterol predicts coronary heart disease mortality in older persons. JAMA 274:539-544 